Vietnam Journal of Mechanics, VAST, Vol.34, No. 4 (2012), pp. 247 - 259

\title{
SIMULATION AND OPTIMIZATION OF A SILICON-POLYMER BIMORPH MICROGRIPPER
}

\author{
Phan Huu Phu ${ }^{1}$, Nguyen Ngoc Viet ${ }^{1}$, Nguyen Minh Ngoc $^{1}$, \\ Vu Ngoc Hung ${ }^{2}$, Chu Duc Trinh ${ }^{1}$ \\ ${ }^{1}$ University of Engineering and Technology, VNU, Vietnam \\ ${ }^{2}$ Hanoi University of Science and Technology, Vietnam
}

\begin{abstract}
This paper presents an electrothermally bimorph microgripper based on silicon-polymer laterally stacked structures and then optimized method for decreasing the maximum working temperature, improving temperature profile. The actuated displacement is enhanced due to the polymer constraint effect. Both the thermal expansion and apparent Young's modulus of the constrained polymer blocks are significantly improved, compared with the no constraint one. The device consists of a serpentine-shape deep silicon structure with a thin film aluminum heater on the top and filling polymer in the trenches among the vertical silicon parts. The fabricated bimorph microgripper can operate in four modes and generates a large motion up to $15 \mu \mathrm{m}$. The simulated results are met the fabricated measurements. The output displacement of the optimized structures are increased when the working temperature, power consumption decreases. The simulated results show that the output displacement is increased up to $500 \%$ at 2 $\mathrm{V}$ and temperature profile improved considerably. This electrothermally silicon-polymer opened and closed microgripper can be used in micro-robotics, micro-assembly, minimally invasive surgery, living cells surgery.
\end{abstract}

Keyword: Bimorph actuator, microgripper, polymeric microactuator, silicon-polymer stack, $3 \mathrm{D}$ simulation, temperature profile optimization.

\section{INTRODUCTION}

Microactuators for remote and precise manipulation of small objects are of great interest in a wide variety of applications. The design and development of such microgripper devices would be useful for robotics, microtechnology, precision engineering, defense, energy, and biomedical research, as well as used in medical applications such as minimally invasive surgery, living cell surgery $[1,2]$. Different types of microactuators realized by MEMS technology such as piezoelectric [3,4], electrostatic [5], and electrothermal [6-8] are developed and applied in microgrippers. Generally, electro-thermally actuators are preferred as they use lower driving voltages. Especially the polymeric electro-thermally microgrippers have been widely investigated due to their large displacement at lower driving voltage and operating temperature [6-8]. Most of the developed polymeric microgrippers are based on the unimorph actuator and employed two-material structures. The metal heater is deposited on the top of a high thermal expansion coefficient polymer layer. The 
interface between the heat source and the polymer layer is rather limited by the surface area of the metal layer and the heat transfer along the vertical dimension. Since the polymer layers have low heat conduction rate, the reported structures in ref. $[7,8]$ have limited movement and slow response time. Moreover, the unintended vertical movement couples and interferes with the desired lateral movement of those structures.

This paper presents a novel integrated silicon-polymer in-plane microactuator and optimized structures. The device consists of laterally stacked structures based on a threeelement composite: metal heating layer, heat conducting silicon structures and polymer. The heat is highly efficient transferred from the heater to the polymer by employing the high heat conduction rate of the deep silicon serpentine structures that have a large interface with the surrounding polymer. The proposed device is based on the SU8-2002 polymer with a large thermal expansion coefficient. This design overcomes the weakness of the other designs and it boats a large lateral jaw movement with low coupled vertical motion and fast response time. The device is made on regular silicon wafers with a fabrication process compatible with CMOS technology.

An 3D model is built for simulating and working principle analyzing. The simulated results meet the experimental ones. This model is then used to modify structure in order to reduce working temperature for low temperature applications.

\section{SILICON POLYMER STACK}

Fig. 1 shows the sketch of a silicon polymer block. It consists of laterally stacked silicon-polymer segments. Each segment is formed by a rectangular plate of polymer which is bonded between two silicon plates. The metal heater is on the top of the silicon. During

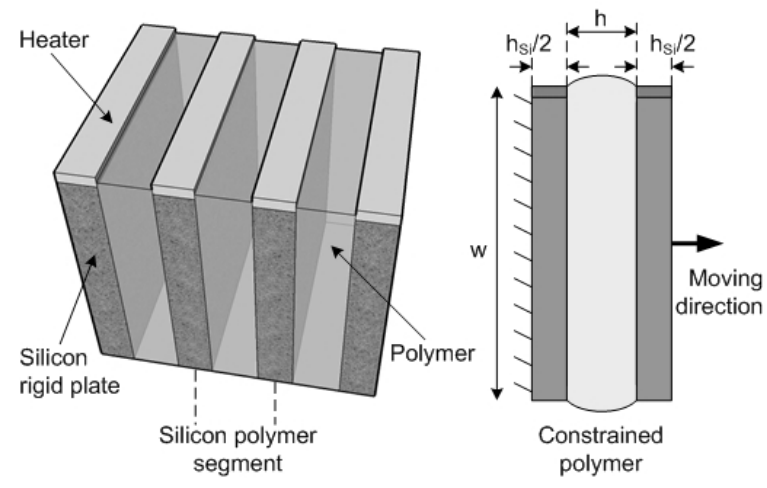

Fig. 1. (a) Scheme of the silicon polymer laterally stacked segments; (b) Cross-side view of a single segment depicting the constrained polymer between two rigid silicon plates [11]

actuation, heat is efficiently transferred from the heater to the polymer thanks to the high thermal conduction of the deep silicon structures that have a large interface with the surrounding polymer. The related properties of Silicon, Aluminum and SU8 are shown in Tab. 1. The thermal expansion of the constrained polymer is three times larger than the no 
constraint one. Polymer layers are bonded between two silicon plates which constrain the expansion of the polymer layer on the direction parallel to the plate surfaces. Therefore, the thermal expansion of the polymer plate is enhanced in the perpendicular direction. The polymer constraint effect analysis based on the hydrostatic pressure theory was introduced in $[9,10]$.

Table 1. Properties of Silicon, Aluminum and SU8

\begin{tabular}{|l|r|r|r|r|}
\hline Parameters & $\mathrm{Si}[14-17]$ & $\mathrm{SU} 8[12,18-20]$ & $\mathrm{Al}[21-23]$ & $\mathrm{Unit}$ \\
\hline Young's modulus & 170 & 3.2 & 70 & $\mathrm{GPa}$ \\
Thermal conductivity & 148 & 0.2 & 237 & $\mathrm{~W} / \mathrm{m} / \mathrm{K}$ \\
Poisson's ratio & 0.22 & 0.33 & 0.33 & - \\
Coefficient of thermal expansion (CTE) & 2.6 & 150.7 & 13.1 & $10^{-6} / \mathrm{K}$ \\
Temperature coefficient of resistance & 1.3 & - & $4.13 \mathrm{e}-3$ & $\mathrm{ppm} / \mathrm{K}$ \\
Resistivity & - & - & 2.65 & $10^{-8} \Omega \mathrm{m}$ \\
\hline
\end{tabular}

The total force, thermal expansion, and apparent CTE of the constrained polymer between two rigid plates are calculated carefully by [10]. Fig. 2 shows the thermal expansion of the constrained polymer block between two rigid silicon plates versus its $w / h$ ratio when the structure is heated from room temperature to $120^{\circ} \mathrm{C}$ (temperature change is $100^{\circ} \mathrm{C}$ ). The thermal expansion increases as the $w / h$ increases and it is three times larger than the expansion of the no constraint case when the $w / h$ ratio is about 10 [10].

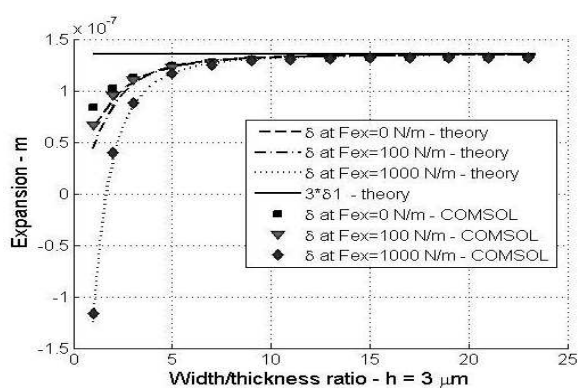

Fig. 2. The thermal expansion of constrained SU8 polymer inside two rigid plates versus the $w / h$ ratio for a temperature change of $100^{\circ} \mathrm{C}$ (from room 20 to $120^{\circ} \mathrm{C}$ ) [11]

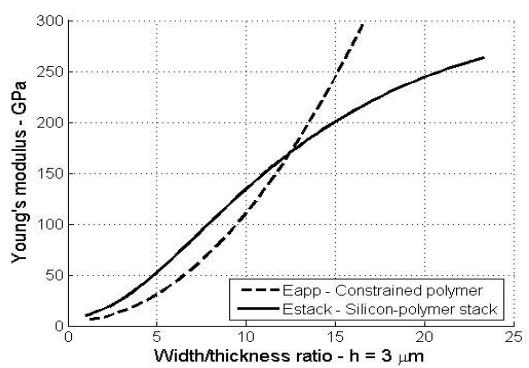

Fig. 3. The apparent Young's modulus of constrained polymer and silicon-polymer stack versus the $w / h$ ratio [11]

Beside the expansion, the apparent Young's modulus of the constrained polymer between two rigid plates is also an importance parameter of the actuator. The apparent Young's modulus of the structure is calculated and shown that it increases with the secondorder of $w / h$ ratio (see Fig. 3) [10]. 


\section{SILICON-POLYMER ELECTROTHERMAL ACTUATOR DESIGN}

SU8 2000 is a high contrast, negative, epoxy-based line of conventional near-ultraviolet (350-400 nm) radiation sensitivity photoresist with suitable chemical and mechanical properties for the envisioned polymer silicon actuator configuration. SU8 allows the fabrication of structures with high aspect ratios and straight sidewalls [12].

A schematic drawing of the bimorph microgripper is shown in Fig. 4. An actuator arm consists of 80 couples of silicon-polymer segments. The silicon and polymer layers are $3 \mu \mathrm{m}$ wide, $100 \mu \mathrm{m}$ long and $50 \mu \mathrm{m}$ thick. The ratio between the width of the polymer layer and the dimensions of its bonded surface with the silicon rigid plate are 33 and 16, respectively. These ratio values satisfy the prerequisite for the maximum constraint effect (see Figs. 2 and 3). The bimorph actuator is constructed by combining the silicon-polymer stack and the bone cantilever. The polymer layers expand laterally due to the constraint effect causing a bending displacement of the actuator arm [10]. Other parameters related to the geometry of the fabricated microgripper are shown in Fig. 4 and Tab. 2.

The device consists of serpentine-shape deep silicon structures with thin-film metal heater layers on the top and the trenches among the vertical silicon parts are filled with the polymer. The structure can be compared to the human body. In fact the thin film metal heater is an electrical energy to heat energy converter. It plays a role as the digestive system in the body. The serpentine-shape deep silicon structure is the frame of the device and the heat conducting environments. It corresponds to both the bone and circulatory systems. The polymer parts, where the heat energy is transformed to mechanical motion, are the muscle system [13].

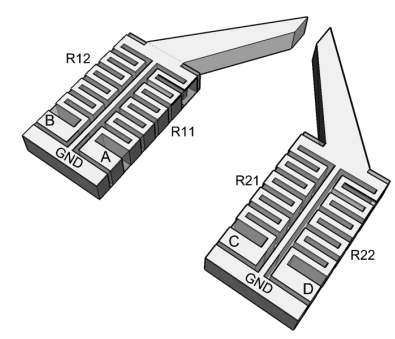

Fig. 4. Design of the bimorph microgripper

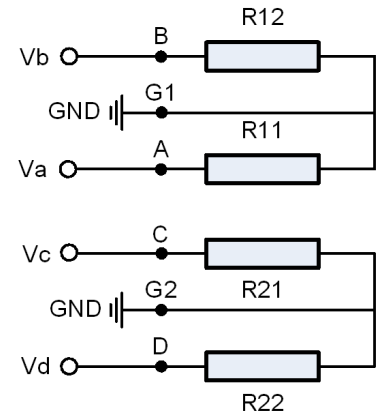

Fig. 5. Schematic drawing of the bimorph microgripper circuits

Fig. 4 shows a detail of the silicon-polymer electrothermal microactuator. The silicon bones are surrounding by the SU8 polymer as the muscle component. Instead of heat transferring directly from the heater to the polymer as the case in other designs [6-8], the circulatory system efficiently distribute the heat to the polymer muscle through the large interface areas between the silicon structures and the polymer. The lateral stacks expand along the lateral direction when it receives heat energy. 
The bimorph actuator is a combination of two lateral stacks and the silicon beam in the middle (see Fig. 4). The bimorph bends when a stack is activated by applying a voltage to the corresponding heater.

Table 2. Geometry of the silicon-polymer electrothermal microgripper based on the serpentine structure

\begin{tabular}{|l|r|r|}
\hline Parameters & Value & Unit \\
\hline Actuator length & 500 & $\mu \mathrm{m}$ \\
Actuator thickness & 50 & $\mu \mathrm{m}$ \\
Silicon serpentine length & 100 & $\mu \mathrm{m}$ \\
Silicon serpentine width & 3 & $\mu \mathrm{m}$ \\
Silicon bone structure width & 5 & $\mu \mathrm{m}$ \\
SU8 layer width & 3 & $\mu \mathrm{m}$ \\
Aluminum heater thickness & 600 & $\mu \mathrm{m}$ \\
Microgripper jaw length & 215 & $\mu \mathrm{m}$ \\
Microgripper jaw width & 170 & $\mu \mathrm{m}$ \\
Microgripper tip width & 30 & $\mu \mathrm{m}$ \\
\hline
\end{tabular}

Table 3. Operation modes of the bimorph microgripper

\begin{tabular}{|l|c|c|c|c|l|}
\hline Mode & $V a$ & $V b$ & $V c$ & $V d$ & Operation mode \\
\hline 1 & $\mathrm{C}$ & $\mathrm{x}$ & $\mathrm{C}$ & $\mathrm{x}$ & Jaw opening \\
2 & $\mathrm{x}$ & $\mathrm{C}$ & $\mathrm{x}$ & $\mathrm{C}$ & Jaw closing \\
3 & $\mathrm{C}$ & $\mathrm{x}$ & $\mathrm{x}$ & $\mathrm{C}$ & Jaw right-shifting \\
4 & $\mathrm{x}$ & $\mathrm{C}$ & $\mathrm{C}$ & $\mathrm{x}$ & Jaw left-shifting \\
\hline
\end{tabular}

$\mathrm{C}$ : Connected to applied voltage $V$ $\mathrm{x}$ : Floating

In Fig. 5, the electronic circuit of the bimorph microgripper is shown. The motion of the jaws of the microgripper corresponds to the applied voltage change. When $V a, V c$ is connected to applied voltage $V$ and $V b, V d$ is opened, two inner stacks $R 11$ and $R 21$ of the microgripper are activated and expanded. Hence, the two jaws of the microgripper are opened. This configuration is called the jaw opening mode. Correspondingly, the microgripper operation is the jaw closing mode when $V a, V c$ is opened and $V b, V d$ is connected to the voltage source $V$. In addition, the microgripper can operate in two other modes as reported in Tab. 3. In mode 3 and 4, the microgripper is working on the shifting mode; i.e. both jaws are shifted to the left or right side of the microgripper.

\section{FABRICATION}

The silicon-polymer integrated microgripper is fabricated using bulk micromachining techniques in a three-mask process. It and can be divided in five major parts as schematically shown in Fig. 6 [11].
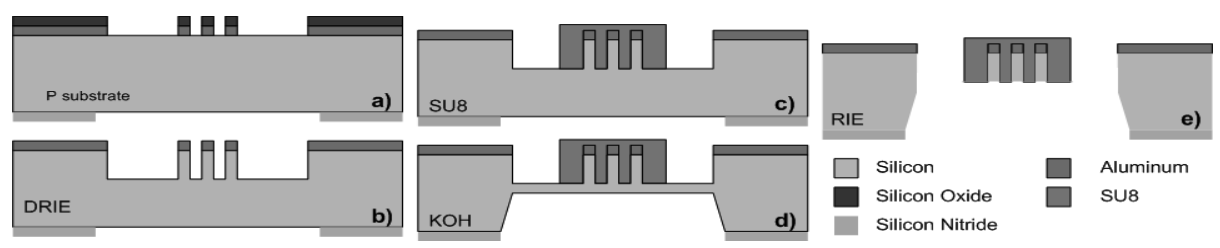

Fig. 6. Schematic view of the fabrication process [13] 
The substrate is a $p$-type $\mathrm{Si}$ wafer on which a LPCVD silicon nitride layer is deposited as the back side masking layer during the anisotropic wet etching of the silicon bulk. On the wafer front side a $600 \mathrm{~nm}$ thick aluminum and a $2 \mu \mathrm{m}$ thick PECVD silicon oxide are deposited and patterned by is patterned and reactive ions etching (RIE) to create the serpentine aluminum heaters (see Fig. 6a). In Fig. 6b, the $50 \mu \mathrm{m}$ deep silicon trenches are created by using deep reactive ion etching (DRIE). Then the silicon oxide mask layer is removed in buffered hydrofluoric acid BHF (1:7) solution. Negative photosensitive SU8-2002 polymer is filled and patterned, as indicated in Fig. 6c. Then, the bulk silicon is etched from the back side in a $33 \mathrm{wt} \% \mathrm{KOH}$ solution at $85^{\circ} \mathrm{C}$ until the thickness of the membrane outside the microgripper structures is about $10 \mu \mathrm{m}$ (see Fig. 6d). The front side of the wafer is protected during the etching in $\mathrm{KOH}$ by using a vacuum holder. Finally, the releasing of structures is done by employing RIE to etch the remaining silicon layer from the backside (see Fig. 6e).

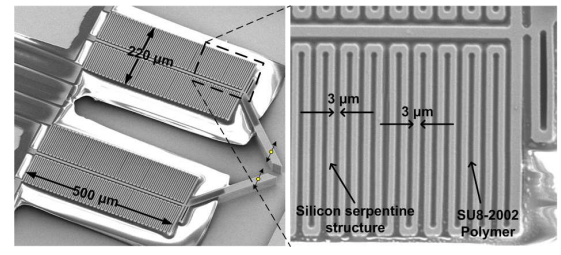

Fig. 7. SEM pictures of the fabricated silicon polymer bimorph microgripper [13]

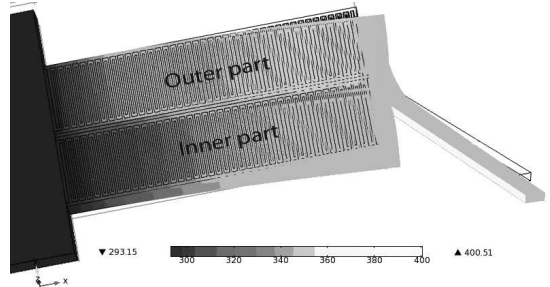

Fig. 8. 3D model of the microgripper

Fig. 7 shows SEM pictures of the fabricated silicon-polymer integrated bimorph microgripper. The actuators are $500 \mu \mathrm{m}$ long, $220 \mu \mathrm{m}$ wide and $50 \mu \mathrm{m}$ high [13]. The geometry of the structure is shown in more detail in the close-up SEM image.

\section{MICROACTUATOR FINITE ELEMENT ANALYSIS}

A finite element modeling tool is used to simulate the operation of this sensing micro-gripper (COMSOL (Comsol Inc.)). The 3D model is used to determine the operat-

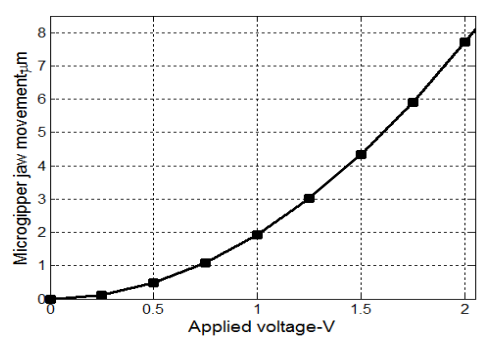

Fig. 9. The simulated jaw displacement versus applied voltage

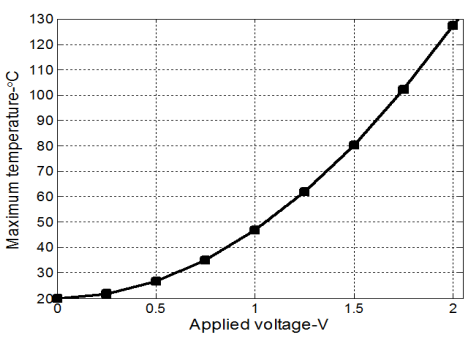

Fig. 10. The simulated maximum temperature versus applied voltage 
ing parameters at steady-state of the silicon-polymer electrothermal microactuator [24-27]. Elasticity, movement, temperature profile, power consumption of the actuator are calculated based on conversion of electricity into heat. A voltage is placed on both ends of the aluminum filament, current flows in the resistor will generate heat that launch the polymer constraint effect. Fig. 8 shows the 3D model of the silicon-polymer electrothermal microgripper which indicates the temperature profile when a applied voltage of $2 \mathrm{~V}$ in the open mode. Figs. 9, 10 and 11 show jaw movement, maximum temperature and power consumption simulation results when a voltage applied between 2 nodes $V a, V c$ to GND.

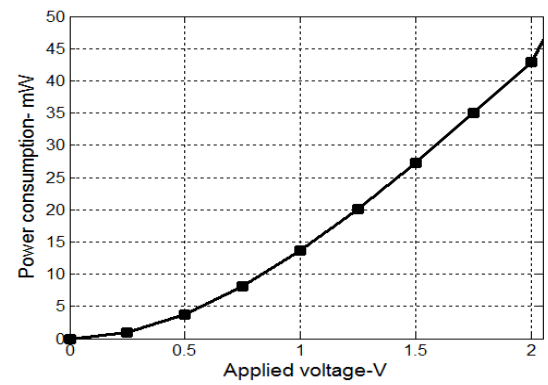

Fig. 11. The simulated power consumption versus applied voltage

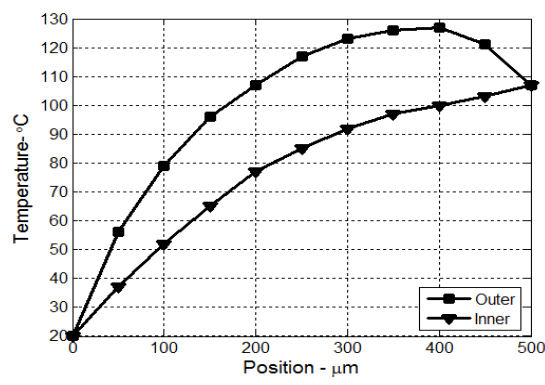

Fig. 12. Simulated temperature profile on the actuator surface when applied voltage of $2 \mathrm{~V}$ in close mode

The steady state temperature profile of the actuator is shown in Fig. 12. In this simulation, a dc $2 \mathrm{~V}$ is applied to the outer filament for closing mode. Although the heat source is located on the outer, the temperature on the inner part is only slightly lower.

\section{MEASUREMENT RESULTS}

The structure is measured by using the Cascade probe station (Cascade Microtech, Inc.) with a built-in microscope to measure the displacement. In order to characterize the electrical actuating characteristic, a dc voltage is applied on the metal heater by using HP4155A semiconductor parameter analyzer (Agilent Technologies, Inc.) [11]. The voltage is ramped form 0 to $2 \mathrm{~V}$. The displacement is monitored through the CCD camera on the top of the probe station. The displacement of the actuator at any actuating voltage is then obtained by enlarging the picture and comparing with the initial picture. The average increasing temperature in the electro-thermal actuator can be estimated by monitoring the change of the resistance of the aluminum heater.

In addition, the thermal actuating characteristic of the actuators is also investigated by using a built-in external heat source of the probe station. The investigated temperature range is from 20 to $120^{\circ} \mathrm{C}$ with a $20^{\circ} \mathrm{C}$ step and an accuracy of $\pm 0.1^{\circ} \mathrm{C}$. This externally supplied thermal energy causes expansion in the constrained polymer layers and the resulting actuation.

To determine the mechanical performance, the microgripper is activated by dc voltage and the displacement is monitored under an optical microscope. Fig. 13 shows the 
movement of the microgripper jaws versus the applied voltage in the air. This movement corresponds to the total change between the two microgripper arms when both arms are activated in jaw closing mode (see Tab. 3). A maximum movement of $7.7 \mu \mathrm{m}$ is measured at $2 \mathrm{~V}$ applied voltage. Combining the jaw opening and closing mode, the bimorph microgripper jaw movement is twice the movement of the single mode. This means that the maximum movement in combining mode is about $15 \mu \mathrm{m}$ at the applied voltage of $2 \mathrm{~V}$. This measured value is met the simulated result in Fig. 9.

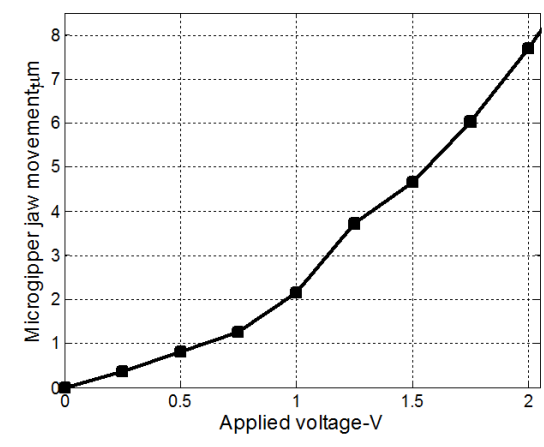

Fig. 13. The microgripper jaw movement versus applied voltage in close mode. The maximum movement is $7.7 \mu \mathrm{m}$ at $2 \mathrm{~V}$

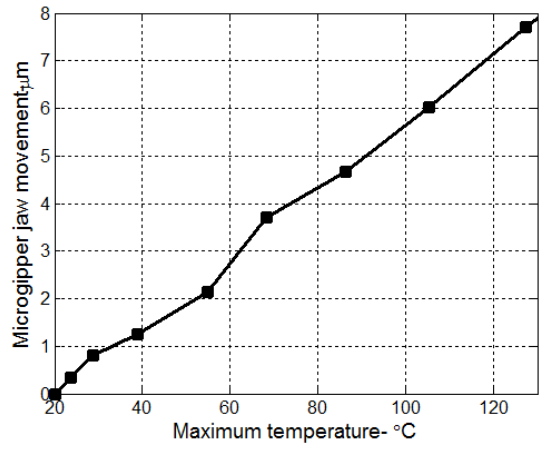

Fig. 14. The movement jaw versus temperature of microgripper. A movement up to $7.7 \mu \mathrm{m}$ at $127^{\circ} \mathrm{C}$

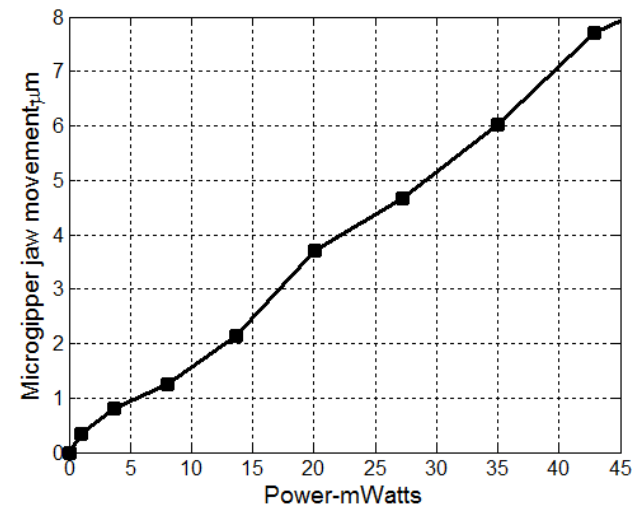

Fig. 15. The microgripper jaw movement versus power consumption

The working temperature of the actuator is determined by monitoring the change of the resistance of the aluminum layer used as the heater. Fig. 14 shows the relation between the measured jaw movements versus the working temperature of the device. The maximum jaw movement of the microgripper is $7.7 \mu \mathrm{m}$ at $127^{\circ} \mathrm{C}$. This microgripper works at low driving voltage and low temperature. Therefore, this device can potentially be biocompatibly operated. The power consumption is calculated through the applied voltage and the corresponding current. Fig. 15 shows that the device needs about $5.7 \mathrm{~mW}$ for 1 
$\mu \mathrm{m}$ of movement.

\section{TEMPERATURE PROFILE OPTIMIZATION}

Fig. 12 shows the temperature profile on active part and inactive part (corresponded to the outer and inner in Fig. 17, respectively). It shows that the heat is conducted form the active part to the inactive through the middle structure. Therefore, temperature on the inactive part is only slightly lower than the active one. It reduces the movement results of the actuator.

Fig. 12 also shows that the temperature distribution is uneven so that the tips displacement is mostly created by some higher temperature silicon-polymer stack. Stacks that closer to the anchor are low temperature consequently not contribute much for the output displacement.

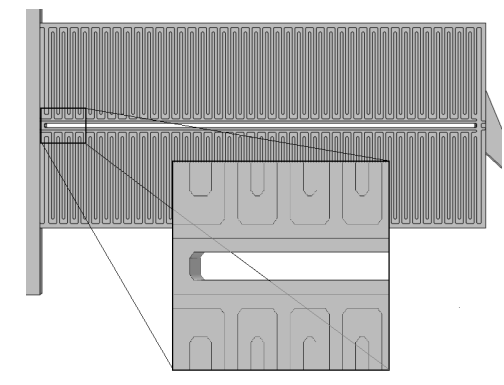

Fig. 16. Removing silicon between two rows of silicon-polymer stacks

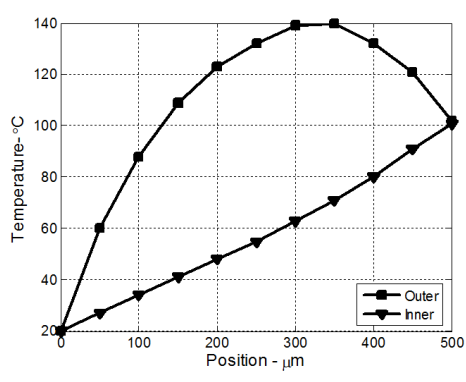

Fig. 17. Temperature profile of the actuator's arm with for structure in Fig. 16 in close mode, applied voltage of $2 \mathrm{~V}$

In this section, two modified structures are proposed for improving the temperature profile. The first method is inserted of an airgap between the two sides of the actuator for limiting the heat diffusion from active to inactive part of the actuator (see Fig. 16). The airgap with the width of $20 \mu \mathrm{m}$ is located between the two parts therefore it isolates the heat energy transfer between each other part.

Fig. 17 shows the simulated temperature profile of this modified structure. It shows that the heat transfer from the active part to the inactive one is significantly reduced when compared with the profile in Fig. 12.

Modifying the structure of the actuator has improved very much the displacement of this gripper, but the temperature tends to rise toward the tip. Heat supply for each silicon stack is assumed equally because of the aluminum strands are designed with same width. Although each comb is provided by the same heat source, the temperature profile does not balance due to the thermal diffusion are uneven in directions. Therefore, the idea of providing a sufficient amount of heat to the necessary positions is concerned. Some preliminary simulation was implemented and showed the change of thermal energy at each position changes displacement and temperature profile as desired. To apply this method 
for this gripper, it is necessary to recalculate the size of the aluminum filament on top of the silicon at each comb. Combs that need more heat the resistor of aluminum wire are smaller, which means the size of aluminum will be wider. This will make huge changes in the structure of the actuator and be reviewed along with the recalculation in terms of mechanical structures optimal such as polymer layer thickness in different locations, the size of the filament, etc. Simplifying to apply this idea, the shunting aluminum wire is done in order to focus and add more heat to stacks that close to the basement. The second method is short-circuit the aluminum heater in the middle to turn off the heatsource that provide to polymer stacks close to the tip of the gripper (see Fig. 18). Shorted point and length of heater wire is calculated and simulated to achieve this optimal value. Fig. 19 shows the simulated temperature profile of this proposed structure. The temperatures of each actuator's side that close to the jaw's tip are almost the same. The temperature differs from each side that close to the substrate is increased much compared to the old structure. This causes the displacement increases.

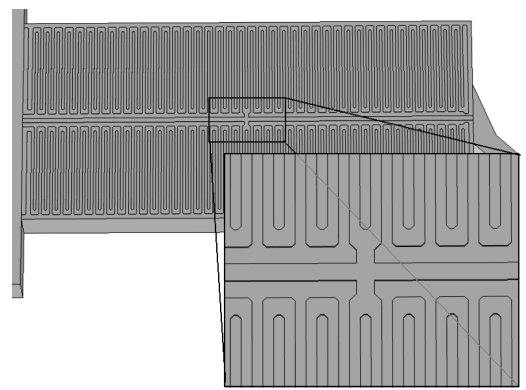

Fig. 18. Short-circuit aluminum structure

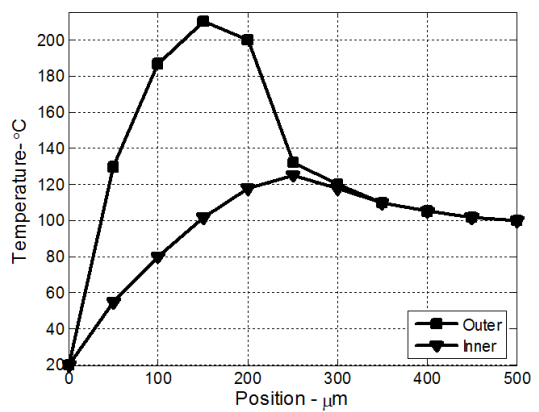

Fig. 19. Temperature profile of the shortcircuit aluminum heater actuator's arm in close mode, applied voltage of $2 \mathrm{~V}$

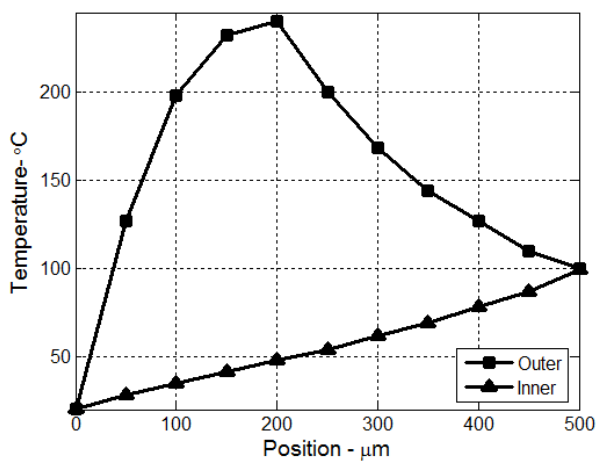

Fig. 20. Temperature profile of the actuator's arm of the combined structure (Figs. 16 and 18) in closing mode, applied voltage of $2 \mathrm{~V}$ 
The third modified structure is a combination of both two above methods. Fig. 20 shows the simulated temperature profile. It shows that temperature at the actuator's tips reduced and therefore the microgrippers's jaws is significantly reduced to around $90^{\circ} \mathrm{C}$. This structure can be used for bioapplication such as living cells surgery.

Table 4. Microgrippers operation

\begin{tabular}{|l|c|c|c|}
\hline Structure & Applied voltage $(\mathrm{V})$ & Jaw displacement $(\mu \mathrm{m})$ & Temperature $\left({ }^{\circ} \mathrm{C}\right)$ \\
\hline Original structure & 1 & 0.96 & 42 \\
Removing Silicon & 1 & 2.35 & 40 \\
Shorting Aluminum wire & 1 & 2.03 & 40 \\
Combination Structure & 1 & 5.23 & 39 \\
Original structure & 2 & 3.85 & 104 \\
Removing Silicon & 2 & 9.40 & 101 \\
Shorting Aluminum wire & 2 & 8.15 & 100 \\
Combination Structure & 2 & 20.5 & 96 \\
\hline
\end{tabular}

The jaws movements are also simulated with the results are shown in Tab. 4. The performances of modified structures are not only improved on the temperature profiles but also on the tip's movement.

\section{CONCLUSION}

A novel bionic design of silicon polymer integrated laterally stack bimorph microgripper is presented, characterized, simulated and optimized. This microgripper can be operated in four modes depended on the electronic configuration. A large movement, up to $15 \mu \mathrm{m}$ at the $2 \mathrm{~V}$ applied voltage, is measured. Three modified structures are presented with the improving performance not only on temperature but also movement characteristics. The finite element analysis (FEA) results show that the movement increased over $500 \%$ and temperature at the jaw tips decreased by $10 \%$ with the same operating conditions. The fabrication process is based on conventional bulk micromachining, polymer filling and is CMOS compatible. The proposed microgripper can potentially be used in micro-robotics, micro-assembly, minimally invasive surgery, living cells surgery.

\section{Acknowledgment}

This work is supported by VNU QG.11.30 project. 
Phan Huu Phu, Nguyen Ngoc Viet, Nguyen Minh Ngoc, Vu Ngoc Hung, Chu Duc Trinh

\section{REFERENCES}

[1] M.C. Carrozza, P. Dario, L. P. S. Jay, Micromechanics in surgery, Transactions of the Institute of Measurement and Control, 4(25), (2003), pp. 309-327.

[2] A. Menciassi, A. Eisinberg, M.C. Carrozza, P. Dario, Force sensing microinstrument for measuring tissue properties and pulse in microsurgery, Trans. Mechatronics, 1(8), (2003).

[3] S. Chonan, Z.W. Jiang, M. Koseki, Soft-handling gripper driven by piezoceramic bimorph strips, Smart Mater. Struct., 5, (1996), pp. 407-414.

[4] M.C. Carrozza, A. Menciassi, G. Tiezzi, P. Dario, The development of a LIGA-microfabricated gripper for micromanipulation tasks, J.Micromech. Microeng., 8, (1998), pp. 141-143.

[5] C.J. Kim, A. P. Pisano, R. S. Muller, Silicon-processed overhanging microgripper, J. MEMS, 1(1), (1992).

[6] D. Yan, A. Khajepour, R. Mansour, Modeling of two-hot-arm horizontal thermal actuator, J. Micromech. Microeng. 13, (2004), pp. 312-322.

[7] N. Chronis, and L.P. Lee, Electrothermally activated SU-8 microgripper for single cell manipulation in solution, J. MEMS,4(14), (2005), pp. 857-863.

[8] N.T. Nguyen, S. S. Ho, and C.L.N. Low, A polymeric microgripper with integrated thermal actuators, J. Micromech. Microeng., 14, (2004), pp. 967-974.

[9] G.K. Lau, J.F.L. Goosen, F. van Keulen, T. Chu Duc, P.M. Sarro, Powerful polymeric thermal microactuator with embedded silicon microstructure, Appl. Phys. Lett., Issue. 21(90), (2007), pp. 214103-3.

[10] T. Chu Duc, G.K. Lau, P.M. Sarro, Polymer constraint effect for electrothermal bimorph microactuators, Appl. Phys. Lett., 10(91), (2007), pp. 101902-3.

[11] Chu Duc Trinh, Sensing microgripper for microparticle handling, PhD dissertation, Delft University of Technology, The Netherlands, (2007).

[12] NANO SU-8 2000 negative tone photoresist formulations 2002-2025 (Newton, MA: MicroChem Corporation)

[13] T. Chu Duc, G. K. Lau, J. Wei, P. M. Sarro, Silicon-polymer laterally stacked bimorph microgripper, 17th MicroMechanics Europe Workshop, pp. 197-200, Southampton, England, 3-5 September 2006. ISBN. 085432-8483.

[14] T. Chu Duc, J.F. Creemer, P.M. Sarro, Piezoresistive cantilever beam for force sensing in two dimensions, IEEE J. Sensors, 1(7), Jan (2006), pp. 96-104.

[15] H. M. Chuang, S. F. Tsai, K. B. Thei, W .C. Liu, Anomalous temperature-dependent characteristics of silicon diffused resistors, Electronics Letters, 13(39), (2003).

[16] J. J .Wortman, R. A. Evans, Young's modulus, shear modulus, and Poisson ratio in silicon and germanium, J. Appl. Phys., 1(36), (1965), pp. 153-156.

[17] J. F. Creemer, P. J. French, The saturation current of silicon bipolar transistors at moderate stress levels and its relation to the energy-band structure, J. Appl. Phys., 96, (2004), pp. 4530-4538.

[18] R. Feng, R.J. Farris, Influence of processing conditions on the thermal and mechanical properties of SU8 negative photoresist coatings, J. Micromech. Microeng., 13, (2003), pp. 80-88.

[19] R. Feng, R.J. Farris, The characterization of thermal and elastic constants for an epoxy photoresist SU8 coating, J. Materials Science, 37, (2002), pp. 4793-4799.

[20] L. J. Gukrin, M. Bossel, M. Demierre, S. Calmes, Ph. Renaud, Simple and low cost fabrication of embedded microchannels by using a new thick-film photoelastic, in Proc. Transducers 1997, (1997), pp. 1419-1422.

[21] J. F. Shackelford, W. Alexander, CRC material science and engineering handbook, Third edition, (2001). 
[22] M. Chinmulgund, R.B. Inturi, J.A. Barnard, Effect of Ar gas pressure on growth, structure, and mechanical properties of sputtered Ti, Al, TiAl, and T\&Al films, Thin Solid Films, 270, (1995), pp. 260-263.

[23] V.E. Zinovev, Handbook of Thermophysical Properties of Metals at High Temperatures, Nova Science Pub Inc, (1996).

[24] P. Phan Huu, T. Chu Duc, Temperature profile optimization for silicon-polymer electrothermal microgripper, International Conference on Advanced Technologies for Communications (ATC), (2011), pp. 311 - 314, ISSN: 2162-1020, Print ISBN: 978-1-4577-1206-7.

[25] Phan Huu Phu, Nguyen Tien Dung, Chu Duc Trinh, Thermal profile optimization and mechanical analysis for a silicon-polymer electrothermal sensing microgripper, The 3rd International Workshop on Nanotechnology and Application - IWNA 2011, 10- 12, November 2011, Vung Tau, (2011), pp. 403-407.

[26] N.D. Mankame, G.K. Ananthasuresh, Comprehensive thermal modelling and characterization of an electro-thermal-compliant microactuator, J. Micromech. Microeng., 11, (2001), pp. 452462.

[27] Q.A. Huang, N.K.S. Lee, Analysis and design of polysiliocn thermal flexure actuator, J. Micromech. Microeng., 9, (1999), pp. 64-70. 